\title{
OPEN Improved NDVI based proxy leaf-fall indicator to assess rainfall sensitivity of deciduousness in the central Indian forests through remote sensing
}

\begin{abstract}
Beependra Singh, C. Jeganathan ${ }^{\bowtie}$ \& V. S. Rathore
Quantifying the leaf-fall dynamics in the tropical deciduous forest will help in modeling regional energy balance and nutrient recycle pattern, but the traditional ground-based leaf-fall enumeration is a tedious and geographically limited approach. Therefore, there is a need for a reliable spatial proxy leaf-fall (i.e., deciduousness) indicator. In this context, this study attempted to improve the existing deciduousness metric using time-series NDVI data (MOD1301; $250 \mathrm{~m} ; 16$ days interval) and investigated its spatio-temporal variability and sensitivity to rainfall anomalies across the central Indian tropical forest over 18 years (2001-2018). The study also analysed the magnitude of deciduousness during extreme (i.e., dry and wet) and normal rainfall years, and compared its variability with the old metric. The improved NDVI based deciduousness metric performed satisfactorily, as its observed variations were in tandem with ground observations in different forest types, and for different pheno-classes. This is the first kind of study in India revealing the spatiotemporal character of leaf-fall in different ecoregions, elevation gradients and vegetation fraction.
\end{abstract}

Tropical forests are well known for their role in global carbon cycle $^{1,2}$, biomass accumulation ${ }^{3}$, regulating climatic services ${ }^{4,5}$, water use in different rooting pattern at different depths $s^{6,7}$ and influencing regional climate including precipitation distribution ${ }^{8}$. The recent abrupt changes in the intensity, frequency and distribution of world's climatic extreme events (drought, heat-wave, forest fires and floods) have adversely impacted the structure and functioning of tropical ecosystems ${ }^{9-11}$. However, deciduous forests of tropical regions are well known for their quick adaptability to xeric conditions and exhibit periodic phenomena like flowering, fruiting, vegetative growth, and leaf-fall at different times of the year which varies with places as per their adaptation to local weather conditions ${ }^{12}$. Although, most trees shed their leaves all through the year, their leave shedding ability (called deciduousness) varies across seasons, but maximum leaf-fall occurs during the dry season. Therefore, deciduousness of tropical forests is considered to be one of the important indicators of climate change due to its strong dependency on rainfall and temperature ${ }^{13,14}$. Thus, understanding the spatio-temporal pattern of deciduousness is useful in predicting carbon dynamics, water use efficiency, nutrient cycle and litter fall of the forest floor. Though many studies ${ }^{15-17}$ have been carried out on vegetation phenology using the traditional ground-based techniques and satellite data, observing a significant change in the phenological behaviour requires a long time observation. However, the intra-annual variations in the weather pattern and its immediate link on the vegetation growth still need further recurring evidence. Importantly, the Central Indian Landscape is highly drought-prone, and tropical deciduous forests have unique ability to quickly adapt to adverse conditions. In this regard, it would be interesting to study the spatial pattern of leaf-fall dynamics in the vast regions of tropical deciduous forests of the central India in different rainfall conditions.

Globally, few studies have been carried out in quantifying deciduousness from remote sensing data. Cuba et al. ${ }^{14}$ studied the spatial pattern of deciduousness over 11 years in Mexican Yucatan forest using Enhanced Vegetation Index (EVI) based metric. We used Normalised Difference Vegetation Index (NDVI) instead of EVI in this study as the NDVI from MODIS and GIMMS has been extensively used for vegetation monitoring ${ }^{15,18-21}$. 


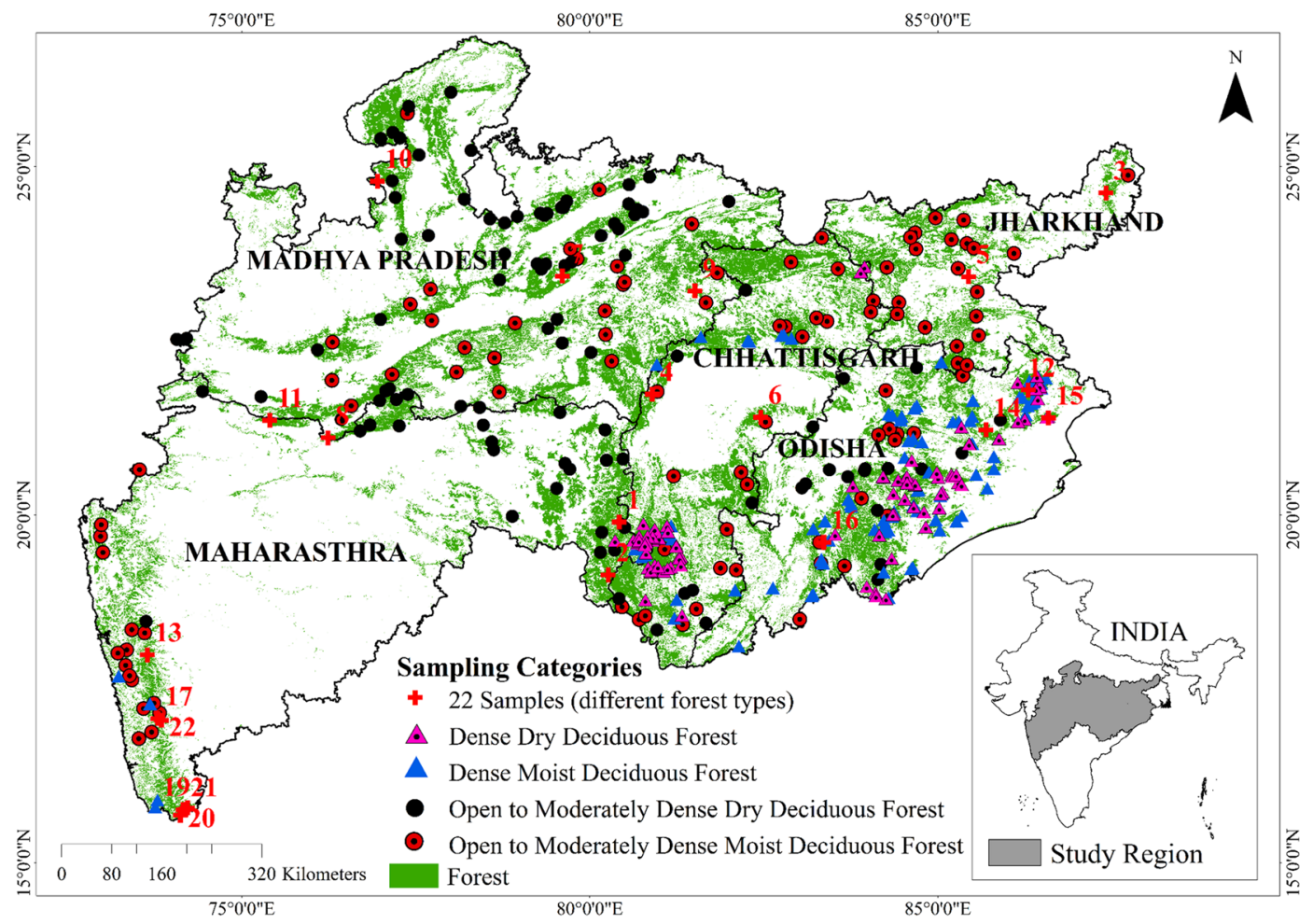

Figure 1. Study area showing distribution of forests with locations of samples from different forest types. (This map was created using ESRI's ArcMap 10.3-https://desktop.arcgis.com/en/arcmap/, and MS-Office PowerPoint 2007 software).

Also, the recent study on phenology by Rankine et $\mathrm{al}^{22}$ in a tropical dry forest observed greater strength of in-situ and MODIS NDVI relationship than EVI.

Gandolfi et al. ${ }^{23}$ discussed the significance of modeling the leaf-fall as it affects the regenerations, growth and helps in maintaining the biodiversity in the under-storey micro-habitat in the long run. Increasing frequency of extreme weather events would affect the photosynthesis, leaf-fall pattern, and hence would alter adaptations and survival strategies of tropical forest under stress conditions. Several studies have reported 10 to $30 \%$ of increase in extreme events (e.g., severe droughts of 2002, 2009, 2014 and 2015) over the Central India ${ }^{24-27}$ which led to increase in forest fires in the dry deciduous forests ${ }^{28-30}$. Moreover, these extreme events will most probably also impact plants natural process of germinations, regeneration and mortality and the entire process of ecological succession in the region. So, it is important to analyze the past and present vegetation conditions, and its resilience and vulnerability towards future climate change scenarios. It is believed that the Central Indian deciduous forest plays an important localized role in controlling monsoon. Thus, any impact on the existence of this forest will probably impact the rainfed agriculture in this region. Evergreen, semi-evergreen, dry deciduous and moist deciduous forests are the major types of forests of the Indian subcontinent where the tropical forest covers maximum land surface area (approximately $69 \%)^{31}$.

The Central Indian deciduous landscape provides shelter for different flora and fauna including the tiger, the important and endangered animal ${ }^{32}$. In addition, it supports huge population for their livelihood, fuel, biomass, medicine, clean water, forest products and other ecological services. This region is also a source of Tendu leaf-Diospyros melanoxylon which is used for manufacturing the "Bidi" (i.e. cigarettes). Millions of the local community in Madhya Pradesh, Odisha and Chhattisgarh are involved in collecting Tendu leaf and non-timber forest products (Madhuca indica) for their livelihood ${ }^{33-35}$. Though, many isolated ground-level studies were carried out to understand the species-level growth pattern ${ }^{12,36,37}$, it is important to know the collective behaviour of a forest at a landscape level rather than the species specific for understanding the regional pattern (Fig. 1) ${ }^{38}$.

In this context, the present study aims to (1) develop a remote sensing based metric which is sensitive and efficient to quantify deciduousness, (2) characterize the deciduousness pattern in the Central India and analyse its spatio-temporal variability and (3) examine the sensitiveness of deciduousness to extreme rainfall conditions.

\section{Results}

Comparison between old and new deciduousness metrics. At first, to check the reliability of the proposed metric, we estimated the deciduousness from the equation proposed by Cuba et al. ${ }^{14}$ (Eq. 1; referred as 'old') and the new metric proposed in this study (Eq. 2; referred as 'new') during the extreme and normal rainfall years. The results of dry and moist deciduous samples and 4 pheno-classes revealed an over-estimation and under-estimation of deciduousness with the old-metric, whereas the new metric revealed the accurate rela- 
(a)

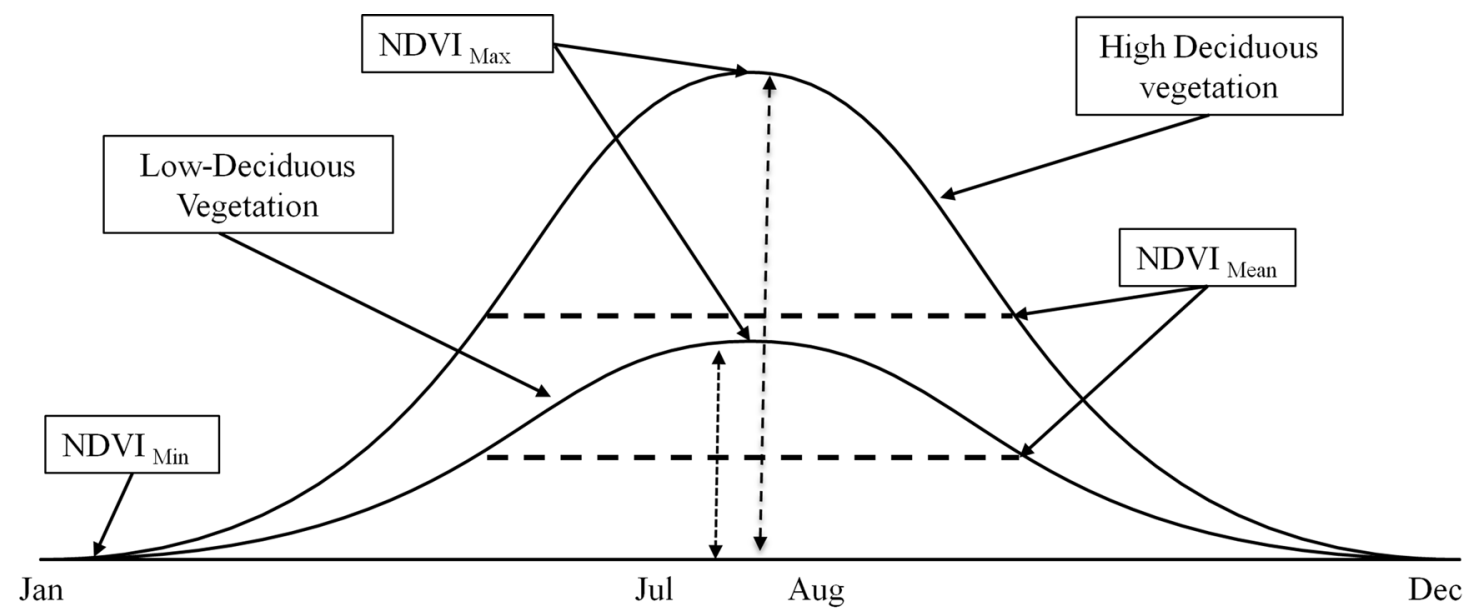

(b)

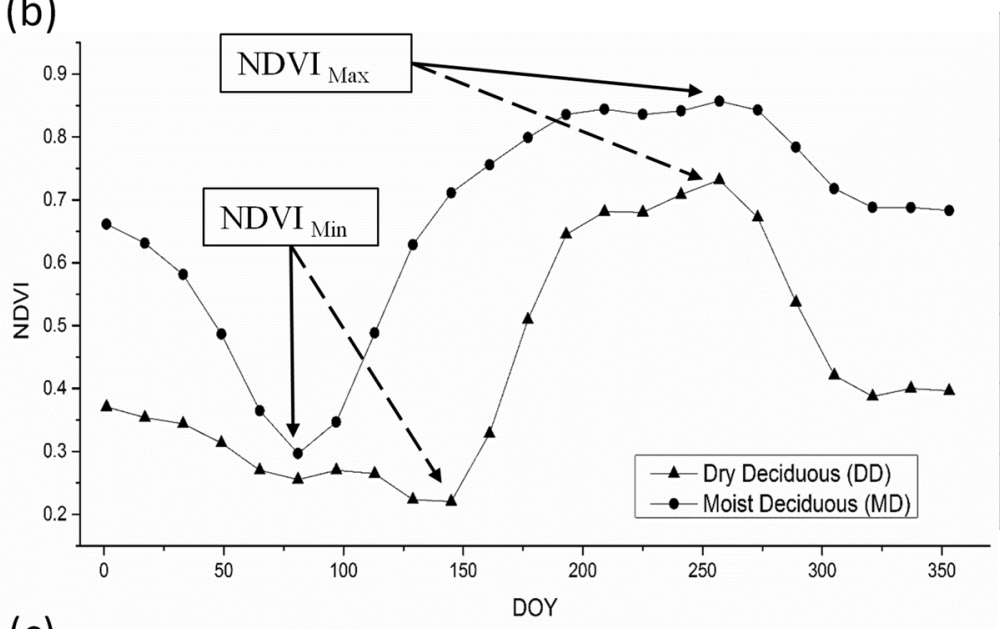

\begin{tabular}{|c|c|c|}
\hline $\begin{array}{c}\text { Vegetation } \\
\text { Characteristics }\end{array}$ & $\begin{array}{c}\text { Dry } \\
\text { Deciduous } \\
76^{\circ} 52^{\prime} 14.9329^{\prime \prime} \\
25^{\circ} 32^{\prime} 16.7100^{\prime \prime} \\
\end{array}$ & $\begin{array}{c}\text { Moist } \\
\text { Deciduous } \\
86^{\circ} 52^{\prime} 52.6400^{\prime \prime} \\
22^{\circ} 03^{\prime} 59.4140^{\prime \prime} \\
\end{array}$ \\
\hline NDVI $_{\text {Min }}$ & 0.2203 & 0.2965 \\
\hline NDVI $_{\text {Max }}$ & 0.7315 & 0.8568 \\
\hline NDVI ${ }_{\text {Mean }}$ & 0.4341 & 0.6682 \\
\hline $\begin{array}{l}\text { Deciduousness } \\
\text { (old metric) }\end{array}$ & $\begin{array}{c}69.89 \\
\text { Over Estimated } \\
\end{array}$ & $\begin{array}{c}65.39 \\
\text { Under Estimated }\end{array}$ \\
\hline $\begin{array}{c}\text { Deciduousness } \\
\text { (new metric) }\end{array}$ & 60.68 & 87.39 \\
\hline
\end{tabular}

(c)

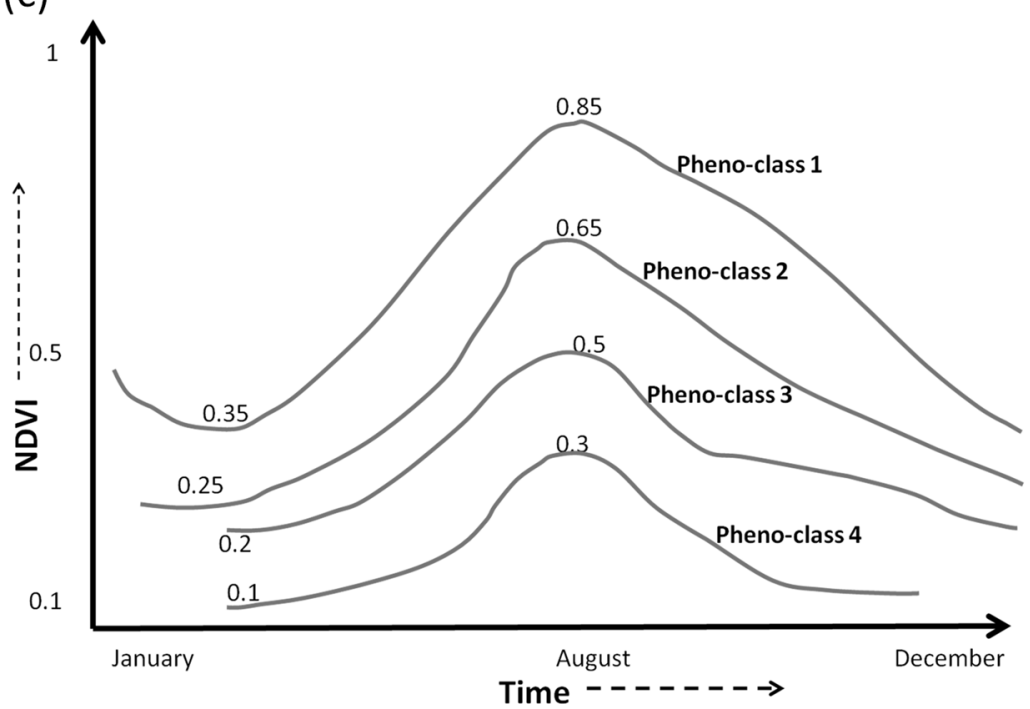

Deciduousness Comparison

\begin{tabular}{|c|c|c|}
\hline Phenotype & Old Metric & New Metric \\
\hline Pheno-class 1 & 58.82 & 70.59 \\
\hline Pheno-class 2 & 61.54 & 55.38 \\
\hline Pheno-class 3 & 60 & 42 \\
\hline Pheno-class 4 & 60 & 20.4 \\
\hline
\end{tabular}

Time $------\rightarrow$

Figure 2. Graphical illustration of deciduousness estimation: (a) Theoretical phenology curves from high and low deciduous vegetation and the parameters of deciduousness, (b) Actual RS derived annual growth profiles of moist and dry deciduous vegetation and their deciduousness estimation using the old and new metric, and (c) Annual growth profile of four theoretical pheno-classes for depicting the different magnitude of deciduousness.

tive variability (Fig. 2b,c, Table S1). Table 1 provides the estimated deciduousness values from the old and new metrics for 22 homogeneous sample pixels representing four major vegetation types in the study area (refer Fig. 1 for their spatial locations and Fig. S1 for their annual growth profile). The litter fall information collected from literature revealed a higher litter fall quantity of $10-14.4 \mathrm{Mg} \mathrm{Ha}^{-1} \mathrm{year}^{-1}$ for the moist deciduous forest ${ }^{39-42}$ 


\begin{tabular}{|c|c|c|c|c|c|c|}
\hline Sample ID & Forest types & NDVI $_{\text {Min }}$ & NDVI $_{\text {Max }}$ & NDVI $_{\text {Mean }}$ & Old metric & New metric \\
\hline S1 & \multirow{6}{*}{ Moist deciduous (MD) } & 0.4438 & 0.8555 & 0.6668 & 48.13 & 64.18 \\
\hline S2 & & 0.5126 & 0.9211 & 0.7515 & 44.35 & 66.66 \\
\hline S3 & & 0.5247 & 0.8587 & 0.7252 & 38.90 & 56.42 \\
\hline S4 & & 0.3989 & 0.8510 & 0.6054 & 53.12 & 64.31 \\
\hline S5 & & 0.4010 & 0.7779 & 0.5942 & 48.44 & 57.57 \\
\hline S6 & & 0.4346 & 0.8421 & 0.6845 & 48.39 & 66.25 \\
\hline S7 & \multirow{5}{*}{ Dry deciduous (DD) } & 0.2645 & 0.6636 & 0.4141 & 60.14 & 49.80 \\
\hline S8 & & 0.2390 & 0.6656 & 0.4082 & 64.09 & 52.32 \\
\hline S9 & & 0.2585 & 0.7127 & 0.4322 & 63.73 & 55.09 \\
\hline S10 & & 0.1907 & 0.6631 & 0.3604 & 71.24 & 51.34 \\
\hline S11 & & 0.2592 & 0.5640 & 0.4034 & 54.04 & 43.60 \\
\hline S12 & \multirow{6}{*}{ Semi-evergreen (SE) } & 0.7198 & 0.8871 & 0.8045 & 18.86 & 30.35 \\
\hline S13 & & 0.7423 & 0.8379 & 0.8020 & 11.42 & 18.31 \\
\hline S14 & & 0.7226 & 0.8730 & 0.8133 & 17.23 & 28.02 \\
\hline S15 & & 0.7886 & 0.9094 & 0.8494 & 13.28 & 22.56 \\
\hline S16 & & 0.7400 & 0.8845 & 0.8212 & 16.34 & 26.84 \\
\hline S17 & & 0.7022 & 0.8564 & 0.7819 & 18.01 & 28.16 \\
\hline S18 & \multirow{5}{*}{ Evergreen (E) } & 0.8033 & 0.8434 & 0.8180 & 4.75 & 7.78 \\
\hline S19 & & 0.7959 & 0.8551 & 0.8213 & 6.92 & 11.37 \\
\hline S20 & & 0.7615 & 0.8446 & 0.8091 & 9.83 & 15.91 \\
\hline S21 & & 0.8002 & 0.8645 & 0.8244 & 7.44 & 12.26 \\
\hline S22 & & 0.7928 & 0.8398 & 0.8167 & 5.60 & 9.15 \\
\hline
\end{tabular}

Table 1. Performance of old and new deciduous metric in a normal rainfall year (2011) using 22 samples from different vegetation types (spatial locations of these samples can be seen in Fig. 1).

and lower litter fall quantities of 1-8.65 $\mathrm{Mg} \mathrm{Ha}^{-1}$ year $^{-1}$ and 5.63-7.84 $\mathrm{Mg} \mathrm{Ha}^{-1}$ year ${ }^{-1}$ for the dry deciduous forest $^{42-44}$ and the semi-evergreen and evergreen forest ${ }^{44}$, respectively. The new metric showed a relatively similar variability in deciduousness to ground observations especially for the moist and dry-deciduous forests than the old metric (Table 1).

Further, the difference between the old and new metric was spatially checked and is shown at the center of Fig. 3 , and the actual values are presented in the surrounding in eight different sub-set locations. The difference image denotes the under-estimated (70.76\% of forest area) and the over-estimated (29.23\% of forest area) deciduousness obtained by the old metric (Fig. 3). The under-estimated area observed was mainly in the moist forested regions of states- Chhattisgarh, Odisha, and Jharkhand states, whereas, the over-estimated area observed was mainly in the dry forested region of states-Madhya Pradesh, Maharashtra, Northern Chhattisgarh and some parts of Jharkhand (Fig. 3). The over- and under-estimations are with respect to the new metric, and not with the real in-situ measurements. However, the new metric is in good agreement with annual growth profiles of different vegetation types, and have positive relation with ground litter fall observations ${ }^{39-44}$.

The deciduousness derived from these two metrics were also tested for their statistical significance using ANOVA (Table 2). In this test 800 stratified random samples belonging to different deciduous forests of different density classes for dry (2002), normal (2011) and wet (2013) years were used. It was found that the mean deciduousness values from the old metric were similar in the majority of the cases and different rainfall conditions. Hence, it could not be used for understanding rainfall impact on the deciduousness. On the other hand, the new metric performed better than the old metric in terms of its variability under (a) different rainfall conditions $(p<0.001)$, (b) different vegetation types $(p<0.001)$ and $(c)$ different forest densities $(p<0.05)$. Thus, we used the new metric for further analysis to get a greater detail about the deciduousness behaviour of the Central Indian forests.

Spatio-temporal distribution and variation in deciduousness. We estimated Annual Deciduousness (AD) and Relative Annual Deciduousness (RAD) from 18 years (2001-2018) of MODIS NDVI data, and analysed their spatio-temporal variability in different rainfall scenarios i.e. during dry, normal and wet years (Fig. 4). For description purpose, we grouped deciduousness into four different classes such as: (1) 0-20\% as low deciduousness (LD), (2) 20-40\% as moderate deciduousness (MD), (3) 40-60\% as high deciduousness (HD) and (4) above $60 \%$ as very high deciduousness (VHD). The intra- and inter-annual differences in spatial distribution and magnitude of deciduousness could be attributed to the effect of local, micro to macro-climatic regimes in the landscape.

From the rainfall anomaly pattern of 18 years (Fig. S2), it was observed that the year 2002 received the lowest rainfall, as $98.97 \%$ of the area was under negative anomaly and $47 \%$ of the area was under severe dry condition i.e., rainfall was much less than $(<-20 \%)$ the normal range. The year 2013 received the highest rainfall, where $45 \%$ of the area was under heavy rainfall $(>+20 \%$ of normal rainfall), and in the year 2011 more than $95 \%$ of 


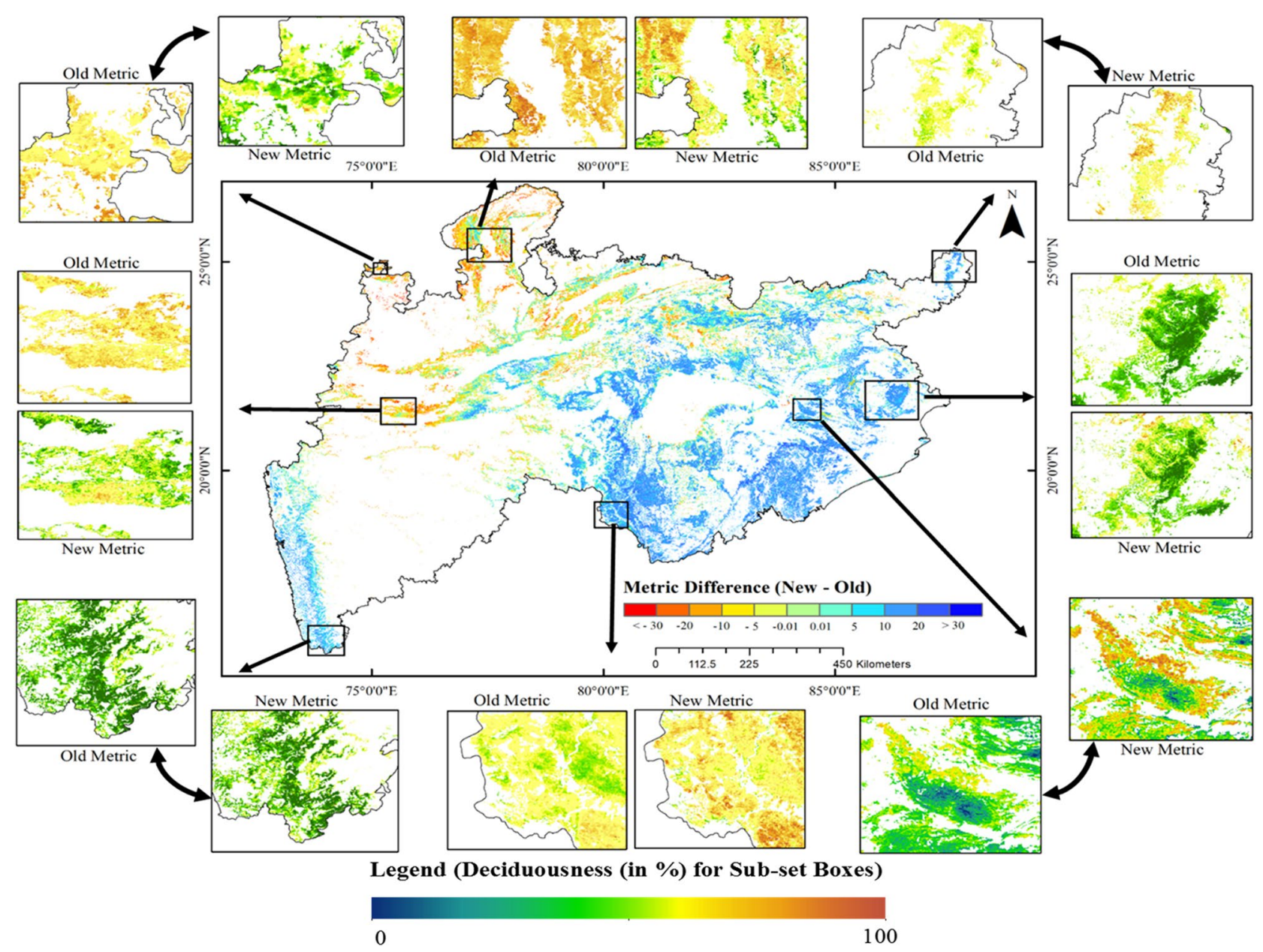

Figure 3. Difference in the spatial distribution of deciduousness (central figure) and the actual deciduousness (subset boxes) derived from the new and old metric for the year 2011. (These maps were created using ESRI's ArcMap 10.3-https://desktop.arcgis.com/en/arcmap/, and MS-Office PowerPoint 2007 software).

the area received normal rainfall. So, these three years (2002, 2011 and 2013) were chosen as the representative years of extreme and normal conditions for further analysis of the deciduousness. During the dry spell around $12 \%$ of the study area experienced lower magnitude of deciduousness (Fig. 4a), especially in the ecoregions like Kathiar-Gir dry deciduous forests, Upper Gangetic plains, north-eastern parts of the Narmada valley, western parts of the Chhota-Nagpur and eastern parts of Eastern highlands. The hotspot pattern of VHD was observed only in the densely forested areas. In the year 2013 (wet year), healthy deciduousness was seen all over the study area with prominence in the Central Deccan Plateau (CDP) (Fig. 4c). A lower magnitude of deciduousness ( 5\%) was observed mainly in the non-deciduous forest types such as evergreen and semi-evergreen.

In the year 2011 (normal year), patches of VHD were observed in the CDP and some parts of the ChhotaNagpur Region (Fig. 4b). Based on the long-term (18 years) mean deciduousness analysis around $36.85 \%$ of the forested area exhibited VHD (Fig. 4d), which was distributed as $11.5 \%, 8.82 \%, 8.13 \%, 5.16 \%$ and $3.24 \%$, in states- Madhya Pradesh, Maharashtra, Chhattisgarh, Odisha and Jharkhand, respectively. The spatial distribution of long-term deciduousness (Fig. $4 \mathrm{~d}$ ) revealed a dominant deciduous nature of vegetation in this region. However, the high values of VHD were observed in the central-southern part of the study area and the low values in the evergreen and semi-evergreen forests of the Western Ghats and Similipal area of the Odisha state (Fig. 4d).

The yearly deciduousness images were classified into different categories and the variations observed during extreme years are listed in Table 3. The area statistics of deciduousness for all 18 years is provided in the supplementary data (Table S2). During the dry year, the forest area under VHD category was about $34.38 \%$ but in the normal year, it increased to $42.38 \%$. In the wet year, it was the highest (51.06\%) under VHD category. The area of deciduousness variability from 2001 to 2018 is presented in Fig. 5. During the study period (18 years), the mean deciduousness was observed to be fluctuating. A clear area reduction in VHD category during the dry years (i.e., 2002 and 2014), and increase during the wet years (2010 and 2017) was observed.

Spatio-temporal distribution and variation in relative deciduousness (RAD). The spatial distribution of RAD derived from annual deciduousness for dry, normal and wet years, respectively is given in Fig. 6a-c. The benchmark deciduousness value at each pixel was computed from 18 years of annual deciduousness (Fig. 6d) and was used to estimate RAD. In the dry year (2002), a high RAD was observed in the CDP 


\begin{tabular}{|c|c|c|c|c|c|c|c|}
\hline & \multirow{2}{*}{\begin{tabular}{|l|} 
Summary \\
Year
\end{tabular}} & \multicolumn{3}{|c|}{ Dry deciduous } & \multicolumn{3}{|c|}{ Moist deciduous } \\
\hline \multirow{8}{*}{$\begin{array}{l}\text { New metric }<30 \% \text { VCF (open to } \\
\text { moderately dense forest) }\end{array}$} & & 2002 & 2011 & 2013 & 2002 & 2011 & 2013 \\
\hline & Average & 57.56 & 60.96 & 64.52 & 56.50 & 59.08 & 62.28 \\
\hline & SD & 10.90 & 8.78 & 9.00 & 9.40 & 10.08 & 9.65 \\
\hline & Variance & 118.83 & 77.05 & 80.94 & 88.35 & 101.53 & 93.17 \\
\hline & Standard error & 1.09 & 0.88 & 0.90 & 0.94 & 1.01 & 0.97 \\
\hline & $\mathrm{F}$ & 13.13 & \multicolumn{2}{|c|}{ (Significant) } & 8.89 & \multicolumn{2}{|c|}{ (Significant) } \\
\hline & F critical & 3.03 & & & 3.03 & & \\
\hline & $P$ value & \multicolumn{2}{|c|}{0.000002} & $\mathrm{~N}=100$ & \multicolumn{2}{|c|}{0.000179} & $\mathrm{~N}=100$ \\
\hline \multirow{7}{*}{$\begin{array}{l}\text { Old metric }<30 \% \text { VCF (open to } \\
\text { moderately dense forest) }\end{array}$} & Average & 61.71 & 61.01 & 62.80 & 51.62 & 52.52 & 52.58 \\
\hline & SD & 7.79 & 9.71 & 8.50 & 10.21 & 11.12 & 10.73 \\
\hline & Variance & 60.62 & 94.19 & 72.19 & 104.32 & 123.66 & 115.08 \\
\hline & Standard error & 0.78 & 0.97 & 0.85 & 1.02 & 1.11 & 1.07 \\
\hline & $\mathrm{F}$ & 1.07 & \multicolumn{2}{|c|}{ (Not significant) } & 0.25 & \multicolumn{2}{|c|}{ (Not significant) } \\
\hline & F critical & 3.03 & & & 3.03 & & \\
\hline & $\mathrm{P}$ value & \multicolumn{2}{|c|}{0.342711} & $\mathrm{~N}=100$ & \multicolumn{2}{|c|}{0.775487} & $\mathrm{~N}=100$ \\
\hline \multirow{7}{*}{$\begin{array}{l}\text { New metric }>40 \% \text { VCF (dense } \\
\text { forest) }\end{array}$} & Average & 55.57 & 52.84 & 56.06 & 49.30 & 46.93 & 51.05 \\
\hline & SD & 9.46 & 10.47 & 9.95 & 11.90 & 11.39 & 12.15 \\
\hline & Variance & 89.42 & 109.52 & 98.92 & 141.59 & 129.76 & 147.51 \\
\hline & Standard error & 0.96 & 1.06 & 1.00 & 1.21 & 1.16 & 1.23 \\
\hline & F & 2.98 & \multicolumn{2}{|c|}{ (Significant) } & 2.98 & \multicolumn{2}{|c|}{\begin{tabular}{|l|} 
(Significant) \\
\end{tabular}} \\
\hline & F critical & 3.03 & & & 3.03 & & \\
\hline & $P$ value & \multicolumn{2}{|c|}{0.052340} & $\mathrm{~N}=98$ & \multicolumn{2}{|c|}{0.052580} & $\mathrm{~N}=97$ \\
\hline \multirow{7}{*}{$\begin{array}{l}\text { Old metric }>40 \% \text { VCF (dense } \\
\text { forest) }\end{array}$} & Average & 38.75 & 35.87 & 38.46 & 34.22 & 32.11 & 34.37 \\
\hline & SD & 7.51 & 7.69 & 7.71 & 9.12 & 8.57 & 8.83 \\
\hline & Variance & 56.47 & 59.10 & 59.45 & 83.17 & 73.41 & 78.03 \\
\hline & Standard error & 0.75 & 0.77 & 0.77 & 0.93 & 0.87 & 0.90 \\
\hline & $\mathrm{F}$ & 4.23 & \multicolumn{2}{|c|}{ (Significant) } & 1.98 & \multicolumn{2}{|c|}{ (Not significant) } \\
\hline & F critical & 3.03 & & & 3.03 & & \\
\hline & $P$ value & \multicolumn{2}{|c|}{0.015516} & $\mathrm{~N}=98$ & \multicolumn{2}{|c|}{0.139391} & $\mathrm{~N}=97$ \\
\hline
\end{tabular}

Table 2. Testing the performance of the old and new metric using ANOVA at different stratification levels.

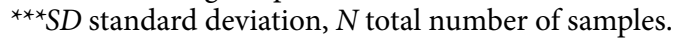

region, and a low RAD was observed in the northern and eastern regions. In the normal year (2011), the majority of vegetation in the northern region showed a high RAD and southeastern region showed a low RAD. During the wet period (2013), a high RAD was observed all over ( $\sim 81 \%$ of the study area) the deciduous forest dominated area than the dry $(\sim 65 \%)$ and normal years $(\sim 75 \%)$.

The area of different RAD classes in percent (ranging from 0 to 100\%) is given in Table 4 and the area of $\mathrm{RAD}$ classes for all 18 years is given in Table S3. In the dry year (2002), the area under the highest RAD class (90-100\%) was about 3.64\% which increased to $5.28 \%$ in the normal year. In the wet year (2013), the highest $\mathrm{RAD}$ area was $7.16 \%$. Though the RAD variations showed a clear link with rainfall pattern, the soil moisture availability also plays a crucial role. Hence, a positive relationship with rainfall in all the deciduous vegetation could not be found out.

Spatio-temporal distribution of rainfall anomalies and their frequency. Figure $7 \mathrm{a}-\mathrm{c}$ reveals the spatial distribution of rainfall anomalies in dry, normal and wet years, and the area statistics of these is given in Table 5. Even in the normal year some regions received low rainfall which is natural as the area is vast. The mean of the yearly rainfall anomaly of 18 years (Fig. S2) revealed that there was more negative anomaly than positive. Nearly $8 \%$ of the study area was under shortage of rainfall. Figure $7 \mathrm{~d}$ shows the long-term average rainfall in the study area.

To analyze the spatial distribution of extreme rainfall at different locations, we estimated the frequency of rainfall anomaly events exceeding $\pm 25 \%$ and $\pm 15 \%$ at every pixel during $2001-2018$. Figure S3a,c show the spatial pattern of the frequency of positive rainfall anomaly events $(>+25 \%$ and $>+15 \%)$, and Fig. S3b, d reveal the frequency of negative rainfall anomaly events $(<-25 \%$ and $<-15 \%)$ in the study area. Overall, the statesMadhya Pradesh (MP) and Maharashtra (MH) experienced a greater number of extreme rainfalls than other states. Around $75 \%$ of the forested area in MP and $61 \%$ of the forested area in $\mathrm{MH}$ experienced $>+25 \%$ rainfall anomaly at least for twice or more. Around 35\% of the forested area in MP and 33\% of the forested area in MH experienced $<-25 \%$ anomaly for at least twice or more in 18 years. Overall, around $20 \%$ of the forested area in the study region was susceptible to extreme rainfall anomaly. 

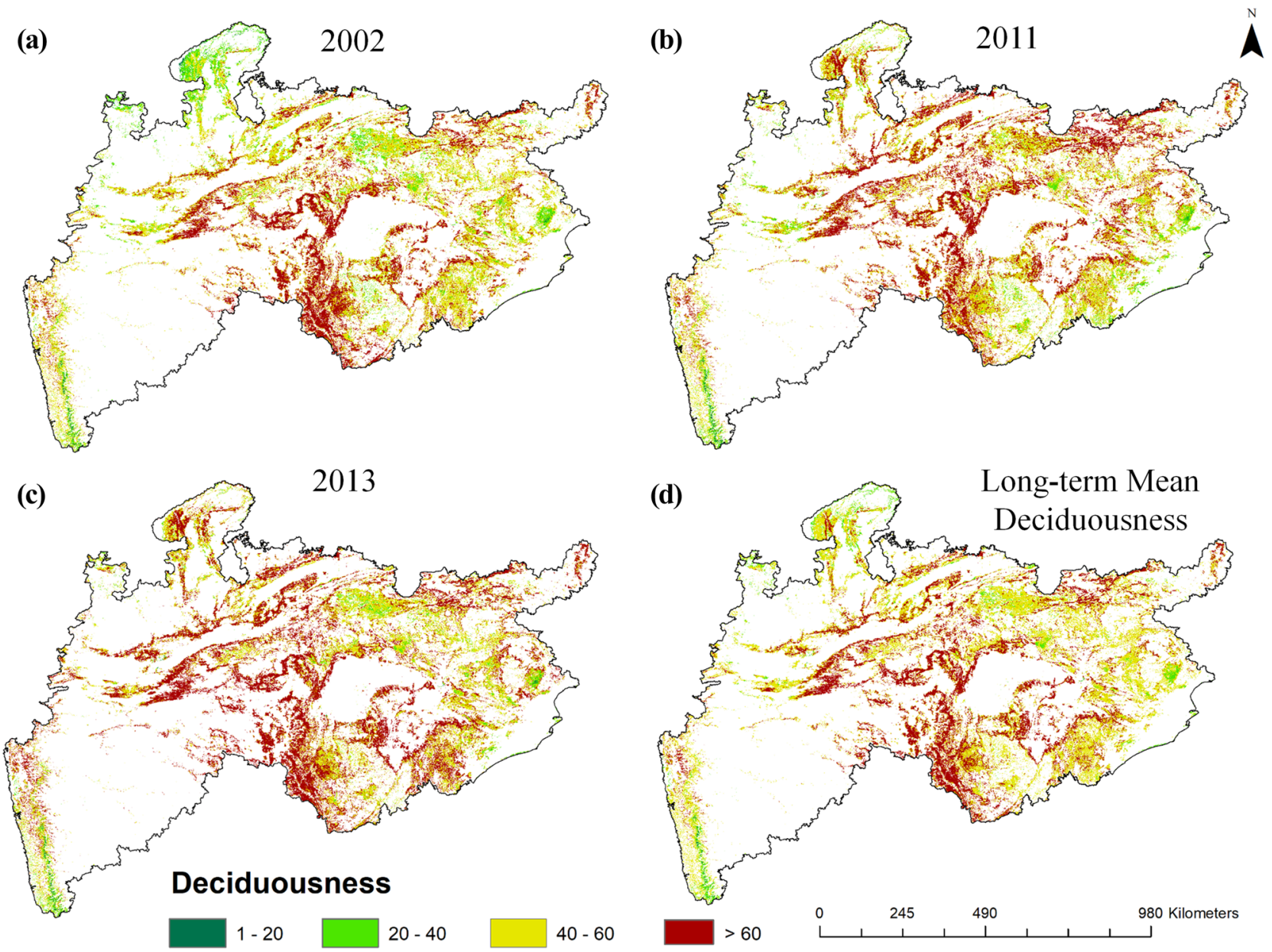

Figure 4. Spatial variability of deciduousness in dry year (2002) (a), normal year (2011) (b), wet year (2013) (c) and long-term mean deciduousness (d). (These maps were created using ESRI's ArcMap 10.3-https://deskt op.arcgis.com/en/arcmap/, and MS-Office PowerPoint 2007 software).

\begin{tabular}{|l|l|l|l|l|l|}
\hline Deciduousness classes & $\begin{array}{l}\text { Deciduousness value } \\
\text { range }\end{array}$ & Dry year (2002) & Normal year (2011) & Wet year (2013) & Long-term mean \\
\hline Low deciduousness (LD) & $(1-20)$ & 0.53 & 0.38 & 0.29 & 0.19 \\
\hline $\begin{array}{l}\text { Moderate deciduousness } \\
\text { (MD) }\end{array}$ & $(20-40)$ & 11.94 & 7.00 & 4.56 & 5.12 \\
\hline High deciduousness (HD) & $(40-60)$ & 53.13 & 50.23 & 44.07 & 57.84 \\
\hline $\begin{array}{l}\text { Very high deciduousness } \\
\text { (VHD) }\end{array}$ & $(>60)$ & 34.38 & 42.38 & 51.06 & 36.85 \\
\hline
\end{tabular}

Table 3. Deciduousness distribution (in \% area) during dry, normal and wet years.

Spatio-temporal distribution of deciduousness in different terrestrial ecoregions. Out of the total 15 terrestrial ecoregions (Fig. S5, classified on the basis of long-term climatic regimes and characteristic plant species ${ }^{45}$ ), only four ecoregions: (1) Narmada valley dry deciduous forests (18\%), (2) Chhota-Nagpur dry deciduous forests (11\%), (3) the Eastern highlands moist deciduous forests (40\%) and (4) Northern dry deciduous forest $(6 \%)$ have the majority of forests $(\sim 75 \%)$ in the study area. Therefore, these four ecoregions were only considered for examining the impact of rainfall variability on the deciduousness in different years (Figs. S4, S5).

The area percentage of different deciduousness classes for these four ecoregions are provided in the supplementary Tables S4, S5, S6 and S7. Forests under VHD class in the Eastern highlands showed a significant influence of rainfall. For the wet years 2003, 2007, 2012 and 2013, the areas estimated under VHD class were 56\%, $47 \%, 56 \%$ and $49 \%$, respectively, which in the dry years $2002,2004,2014$ and 2015 reduced to $37 \%, 35 \%, 19 \%$ and $35 \%$, respectively. The Narmada valley region experiences frequent dry period, and during 2001-2018 the region experienced 7 severe dry periods (i.e., more than $75 \%$ area was under negative rainfall anomaly). During the wet years 2005, 2011 and 2013, VHD areas were 54\%, 49\% and 58\%, respectively, which during the dry years 


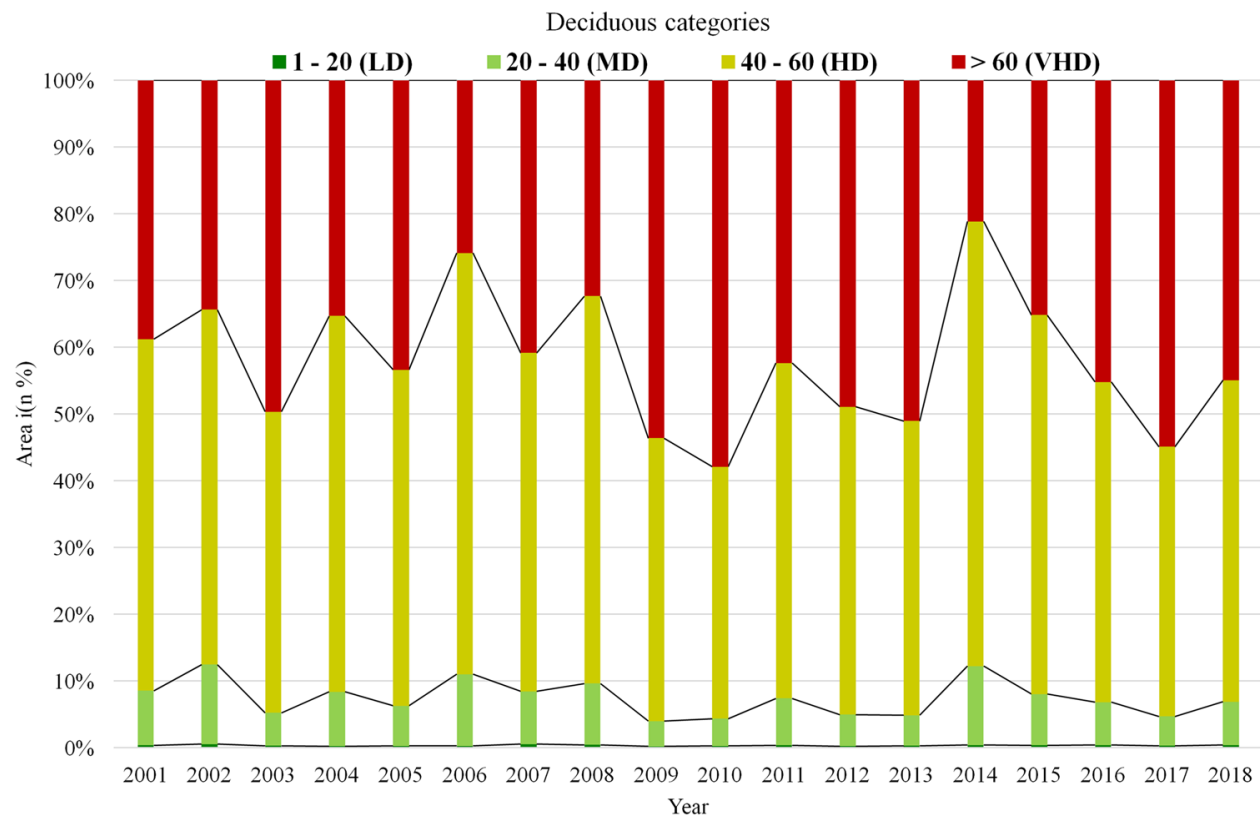

Figure 5. Temporal variation in the percentage area of different categories of deciduousness.
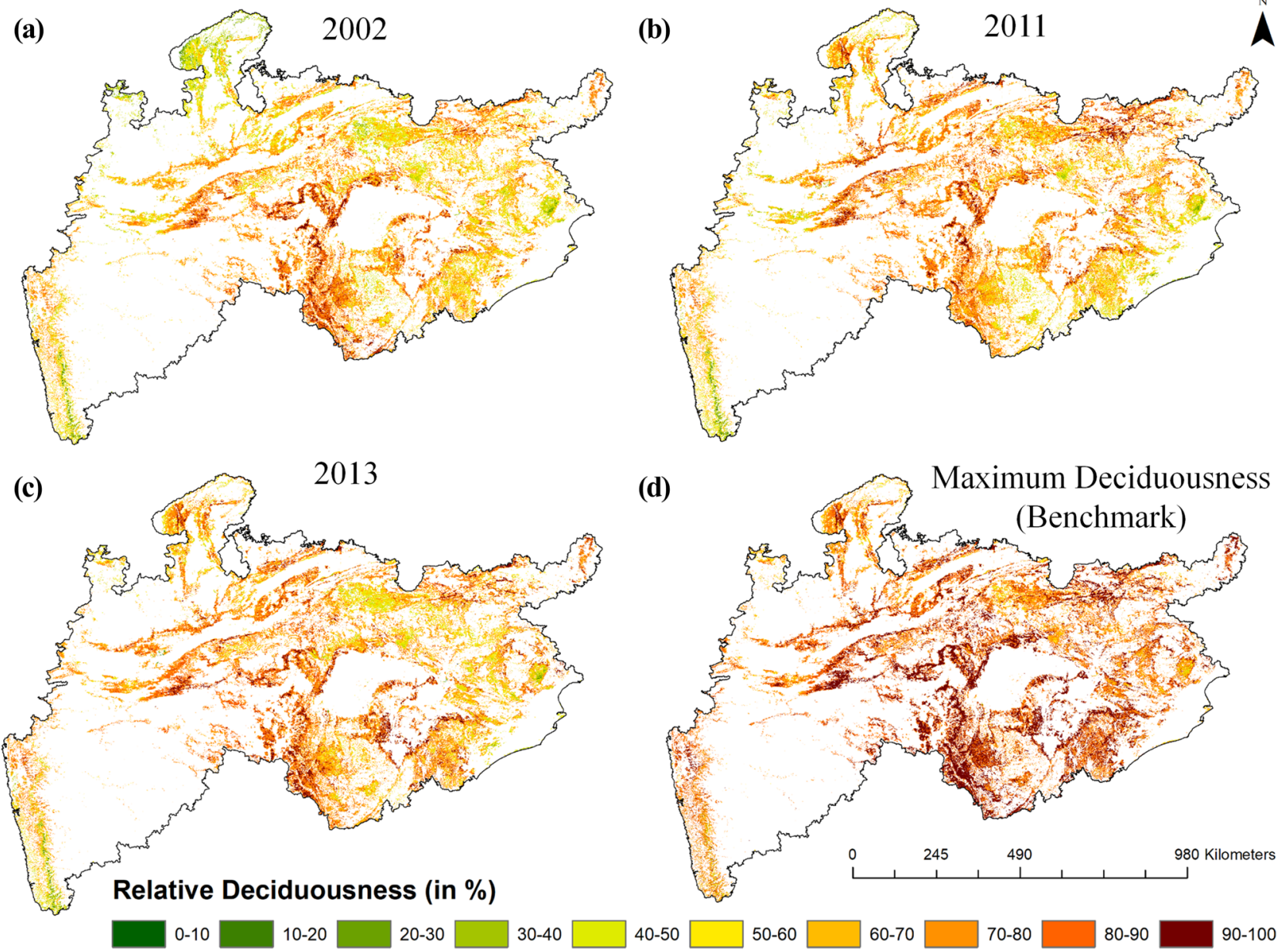

Figure 6. Spatial variability of relative deciduousness (w.r.t benchmark) in dry year (2002) (a), normal year (2011) (b), wet year (2013) (c) and long-term benchmark (d). (These maps were created using ESRI's ArcMap 10.3-https://desktop.arcgis.com/en/arcmap/, and MS-Office PowerPoint 2007 software). 


\begin{tabular}{|l|l|l|l|}
\hline RAD classes & Dry year (2002) & Normal year (2011) & Wet year (2013) \\
\hline $0-10$ & 0.03 & 0.03 & 0.04 \\
\hline $10-20$ & 0.20 & 0.18 & 0.13 \\
\hline $20-30$ & 0.93 & 0.46 & 0.31 \\
\hline $30-40$ & 3.04 & 1.51 & 0.88 \\
\hline $40-50$ & 11.62 & 7.60 & 5.25 \\
\hline $50-60$ & 19.00 & 15.71 & 12.53 \\
\hline $60-70$ & 24.59 & 25.06 & 22.70 \\
\hline $70-80$ & 23.11 & 27.22 & 29.50 \\
\hline $80-90$ & 13.85 & 16.95 & 21.49 \\
\hline $90-100$ & 3.64 & 5.28 & 7.16 \\
\hline
\end{tabular}

Table 4. Relative annual deciduousness (in \% area) during dry, normal and wet years.
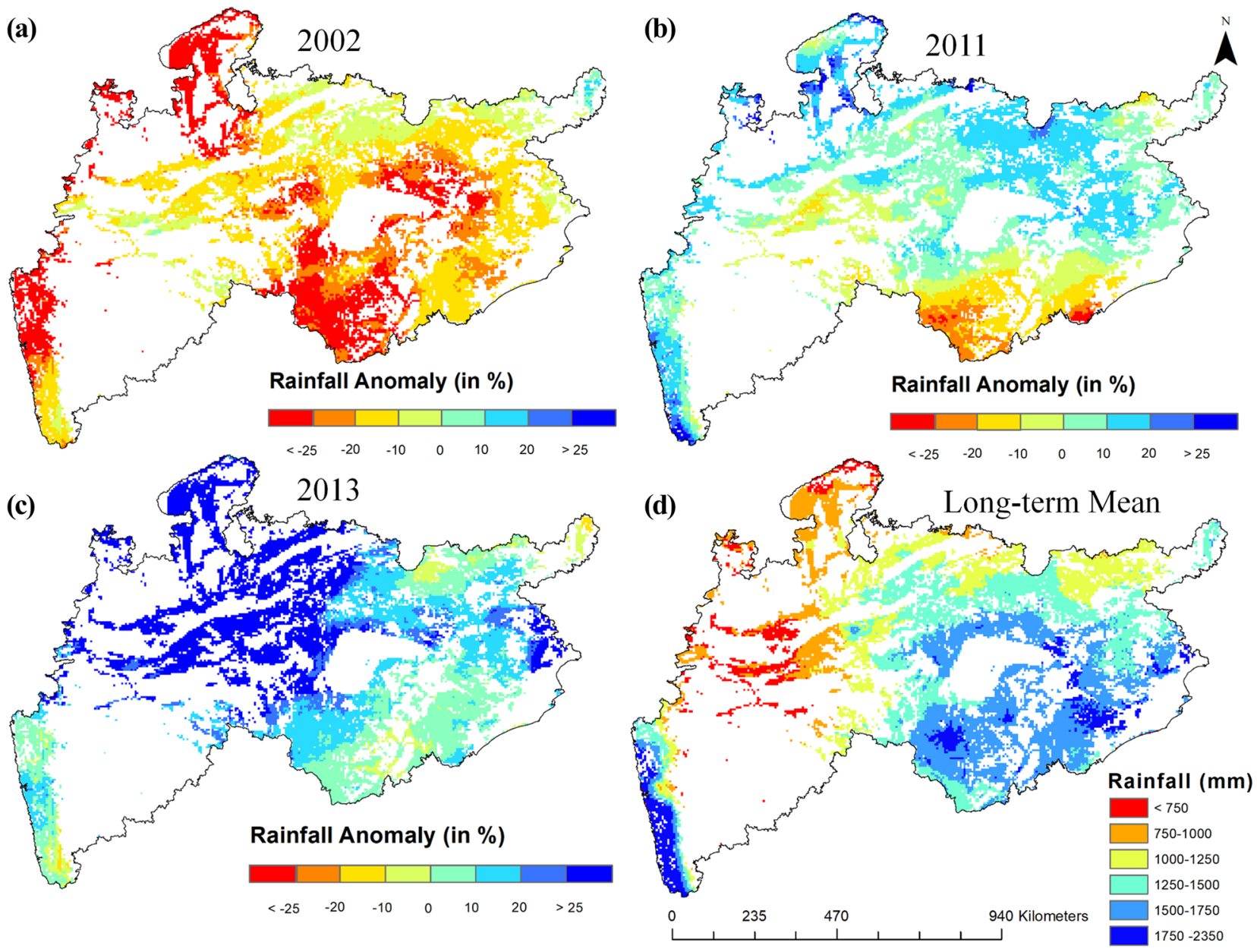

Figure 7. Percentage annual rainfall anomaly in dry year (2002) (a), normal year (2011) (b), wet year (2013) (c) and long-term mean annual rainfall (d). (these maps were created using ESRI's ArcMap 10.3-https://deskt op.arcgis.com/en/arcmap/, and MS-Office PowerPoint 2007 software).

2002, 2004 and 2014 reduced to 30\%, 39\%, and 22\%, respectively in this region. However, the reduction in the deciduousness was not significant during other dry years i.e., 2009, 2017 and 2018 in this region (refer Tables S5 and $\mathrm{S} 9$ for details) which requires further investigation.

A random deciduousness pattern was observed in the Chhota-Nagpur plateau and the Northern dry deciduous region. In these areas, rainfall dependency was not found significant. In the Chhota-Nagpur region, the VHD class areas were $35 \%, 19 \%, 26 \%$ and 55\% during the wet years 2006, 2007, 2008, and 2011, respectively and the areas were $33 \%, 37 \%, 49 \%, 55 \%$, and 17\% during the dry years 2002, 2005, 2009, 2010 and 2014, respectively. In this region, the year 2010 was the driest year but in the same year a high deciduousness ( $54 \%$ of the area) was 


\begin{tabular}{|l|l|l|l|}
\hline Rainfall anomaly classes & Dry year $\mathbf{( 2 0 0 2 )}$ & Normal year (2011) & Wet year (2013) \\
\hline$<(-25)$ & 27.82 & 0.57 & 0.00 \\
\hline$(-25)$ to $(-20)$ & 19.54 & 4.26 & 0.00 \\
\hline$(-20)$ to $(-10)$ & 36.92 & 9.42 & 0.39 \\
\hline$(-10)$ to 0 & 14.69 & 15.66 & 4.90 \\
\hline 0 to 10 & 0.82 & 32.68 & 24.96 \\
\hline 10 to 20 & 0.21 & 32.74 & 24.39 \\
\hline 20 to 25 & 0.00 & 3.34 & 9.06 \\
\hline$>25$ & 0.00 & 1.33 & 36.29 \\
\hline Positive PRA & 1.03 & 70.09 & 94.71 \\
\hline Negative PRA & 98.97 & 29.91 & 5.29 \\
\hline
\end{tabular}

Table 5. Percent rainfall anomaly distribution (in \% area) during dry, normal and wet year.

observed. In the Northern dry deciduous region, the VHD class areas were 51\%, 38\%, 51\% and 56\% during wet years 2001, 2006, 2007 and 2013, respectively and the areas were $46 \%, 40 \%, 59 \%, 43 \%$ and $58 \%$ during the dry years 2002, 2004,2009, 2015 and 2016, respectively. The area of VHD class remained high in the Northern dry deciduous region irrespective of rainfall variability, and it might be due to high ground water table in this region. The Chhota-Nagpur region exhibited an unpredictable deciduousness response with respect to rainfall. Rainfall anomalies in these 4 ecoregions for all the 18 years are provided in the supplementary Tables S8, S9, S10 and S11.

Stratified analysis and sensitivity of deciduousness. Tropical forest species exhibit different phenological strategies to cope with the water shortage and leave shedding during the dry spell $s^{46,47}$. Therefore, to understand the sensitivity of deciduousness towards micro-climatic effect and physical factors, the long-term (LT) mean of the deciduousness (18 years) was grouped into four classes of the deciduousness as mentioned earlier. The area distribution of these classes were: VHD; 36.85\%, HD; 57.84\%, MD; 5.12\% and LD; 0.19\%. Vegetation type-wise variations of the long-term mean deciduousness (Fig. $4 \mathrm{~d}$ ) revealed that out of $\sim 29 \%$ of the major dry deciduous forest area, around $13 \%$ of the area was under VHD and $\sim 15 \%$ of the area under HD class. Out of $\sim 52 \%$ of the major moist deciduous forest area, $\sim 18 \%$ of the area was under VHD and $\sim 32 \%$ of the area under HD class.

The forest density plays an important role in identifying the status of forest health and growth. Thus, we used Vegetation Cover Fraction (VCF) data to classify forest into three different forest density classes: (1) $0-10 \%$ as open forest, (2) 10-40\% as moderately dense forest and (3) above $40 \%$ as dense forest. We analysed the deciduousness in each of the density classes, and observed that in the open density forest class, out of $34.92 \%$ of the forested area only 5.5\% of the area exhibited VHD. In the case of moderate density forest class, out of $60.88 \%$ of the forested area only $31 \%$ of the area exhibited VHD. In the dense forest class, out of $4.21 \%$ of the area only $0.32 \%$ of the area exhibited VHD. The areas under HD in open, moderate and dense forest classes were $26.32 \%$, $28.76 \%$ and $2.79 \%$, respectively. The analysis of long-term mean deciduousness with long-term mean VCF revealed a non-linear relationship (Fig. $\mathrm{S} 6, \mathrm{R}^{2}=0.98$ ). In fact, the deciduousness increased with the increasing canopy density (upto VCF $<25$ ) and then it started to decrease with the high canopy density. Also, the standard error was found to be higher in the lower density values $(\mathrm{VCF}<40)$ than the higher values.

Topography plays an important role in shaping and driving the micro-habitat environment affecting species distribution, biodiversity, primary production and water resources ${ }^{8,48,49}$ and hence the distribution of forested area and their deciduousness in different combinations of rainfall and elevation zones was analysed. We observed that around $90.65 \%$ of the forested area is located in $>200 \mathrm{~m}$ above mean sea level (amsl) and $57.37 \%$ of the forested area is in $>400 \mathrm{~m}$ amsl elevation zones. In different elevation zones of $<300 \mathrm{~m}, 300-600 \mathrm{~m}$, and $>600 \mathrm{~m}$ amsl, the VHD exhibited was $8.95 \%, 22.73 \%$ and $5.16 \%$ of the forested area, respectively. Similarly, in these three elevation zones the HD exhibited was $12.63 \%, 31.59 \%$ and $13.62 \%$ of the forested area, respectively. The maximum deciduousness was observed in the elevation zone of 300-600 m amsl. Around $16.01 \%$ of the deciduous forested area received low rainfall $(<1000 \mathrm{~mm})$ in which $0.95 \%$ area was located in the flat $(\mathrm{FL})$ regions $(<100 \mathrm{~m}), 11.01 \%$ area under medium elevated (ME) region $(200-500 \mathrm{~m}), 3.7 \%$ area under high elevated (HE) region $(500-800 \mathrm{~m})$ and $0.88 \%$ area under very high elevated (VHE) region $(>800 \mathrm{~m})$. Around $42.95 \%$ of the forested area received moderate rainfall $(1000-1500 \mathrm{~mm})$ with the area distribution of $2.45 \%, 24.74 \%, 10.62 \%$ and $5.14 \%$ in different elevation zones like FL, ME, HE and VHE, respectively (Table S12). Around $41.04 \%$ of the area was under high rainfall region $(>1500 \mathrm{~mm}$ ) with the area distribution of $5.44 \%, 19.65 \%, 10.51 \%$, and $5.43 \%$ under FL, ME, HE and VHE zones, respectively. Out of all the forested area around 95\% of the area exhibited high to very high deciduousness in which $35.24 \%$ area was observed in the elevation zone of $>500 \mathrm{~m}$ amsl.

\section{Discussion}

Partitioning the ecosystem in terms of their goods and services especially for carbon sequestrations and water fluxes is an important issue across the world ${ }^{13,50-52}$. Though, the timing of start of greening and end of senescence may not vary drastically in a short-term period in the tropical forests ${ }^{53}$, deciduousness is sensitive to intra and inter-annual micro-climatic variations. Hence, we considered deciduousness as a quasi-indicator to study the 
impact of extreme rainfall conditions on leaf-fall variability. The majority of deciduous vegetation $(\sim 54 \%)$ was observed only in the Central Indian states- Madhya Pradesh and Chhattisgarh, followed by 36\% in Maharashtra (southern Indian state) and Odisha (eastern Indian state). The very high deciduousness was observed dominantly along the border regions of Chhattisgarh, Maharashtra and Madhya Pradesh states (Figs. 4 and 6). Most of the previous studies carried out on the deciduous forests in the study region are either on litter fall variability ${ }^{54,55}$ or phenology ${ }^{56-58}$. However, these studies were carried out through field observations in smaller areas and for shorter temporal periods. Few studies have tried to understand the vegetation response using remote sensing satellite data ${ }^{38,53,59,60}$. In contrast, this study revealed comprehensible yearly differences in magnitude and intensity of deciduousness and its significant link with the rainfall variability at different locations of the study area.

According to Elliot et al. ${ }^{61}$, Williams et al. ${ }^{62}$, and Felton and Smith ${ }^{63}$, the inter-annual variation in the deciduousness was due to physiology, soil-water availability, rainfall, temperature, and relative humidity. In this sense, the spatio-temporal variation in the deciduousness as revealed in this study will help the ecologists to detect the presence of different plants species, relate with species-specific physiology, soil moisture regimes, and landscape resilience. It will also assist in prioritizing the sampling areas for ground-based survey.

Kunhamu et al. ${ }^{64}$ observed that the deciduousness varied linearly with the density of trees. They also found the reduction of leaf-fall from 11.18 to $5.73 \mathrm{Mg} \mathrm{ha}^{-1}$ with decrease of the forest density to a two-third level. However, the present study observed a linear relationship of the deciduousness with the forest density only in the low forest density classes (Fig. S6), not in the high density classes. Also, the study conducted by Jeganathan et al. ${ }^{65}$ revealed considerable differences in the VCF values with FSI published forest density maps in two different forest locations in India. Moreover, the VCF values were not found as the actual representation of the forest density classes. The VCF underestimated both the low and high forest density classes considerably (Fig. S7). Thus, it is suggested that the non-linear relationship between deciduousness and VCF may further be scrutinized and carefully interpreted for Indian forests. The explanation for this observation could be the inclusion of mixed pixels of non-deciduous vegetation types (i.e., presence of evergreen or semi-evergreen vegetation type within the pixel) in the deciduous forest map. According to Singh and Kushwaha ${ }^{66}$ the Shorea robusta (a dominant species in India) has a paradoxical nature and suggested to consider this species under semi-evergreen type. However, the vegetation type map used in this study considered Shorea robusta under deciduous forest (Roy et al. ${ }^{67} 2015$ ), which might have resulted the low deciduousness in high VCF causing a non-linear relationship.

In terms of vegetation growth, two contradicting observations exist in the literature. Condit et al. ${ }^{68}$ and Duan et al. ${ }^{69}$ observed that the magnitude of growth was affected by water availability. While, Elliot et al. ${ }^{61}$ observed that the leaf flushing relied on sub-surface water availability and the rainfall periodicity alone is not the principle determinant in all places of the tropical forests in many parts of the Asia. Interestingly, in this study, we observed the effect of both these factors on the vegetation growth through the deciduousness (Figs. 3 and 4 ). For example, the area under VHD was $34.38 \%$ in the drought year (2002), which increased to $49.67 \%$ in the next year (2003), a high rainfall year. Similarly, there was a clear increase of the deciduousness (51.06\%) in the wet year (2013) than $(42.38 \%)$ in the normal year (2011). The year 2006 received high rainfall in the Central India but the areal extent of VHD class was only 25\%. It reflected the state of dryness, and this was due to the low rainfall in the forest dominant areas. On the other hand, the positive productivity and high deciduousness observed in the drought years (such as 2009) could only be explained properly through the soil moisture information, which can be taken up in our future study. The deciduous vegetation occurring in the lower catchment portion was observed to be independent of rainfall, as the rainfall in the upper catchment invariably brings water downwards. Hence, one should be careful in interpreting rainfall dependencies in such cases.

Further, a high rainfall does not guarantee a high moisture in a region as soil moisture depends on variety of factors such as altitude, slope, soil and its water holding capacity, drainage density, surface runoff, evapotranspiration, and vegetation types. On the other hand, even in the case of shortage of rainfall, presence of high soil moisture due to run off from upper catchment might support the vegetation growth. Overall, high temperature with low rainfall in a poor water-holding soil impacts the magnitude of growth in the study region ${ }^{70}$. It is interesting to note that though $\sim 84 \%$ of this region received more than $1000 \mathrm{~mm}$ of annual rainfall, this landscape is dominated by deciduous vegetation. It is because the mean annual potential evapotranspiration in this region is very high $(>1250 \mathrm{~mm})^{71}$, and hence susceptible to frequent dry periods. Several studies have reported a time-lag between vegetation response to precipitation ${ }^{72-74}$. It is interesting to note that nearly $50 \%$ of the peak growth of deciduous vegetation in the Central India is attained in the beginning of the monsoon period, and during the rainfall period vegetation performs accelerated photosynthesis and biomass accumulation using the abundant sunlight availability in this region. In case of deficiency in rainfall, it gets back to its adaptation mechanism and stops its activities thereby reducing the amplitude of growth. This results in reduction of the deciduousness index.

\section{Conclusion}

The detailed multi-level testing was carried out in this study to reveal the performance of old and new metric and sensitivity of the deciduousness with rainfall variability over 18 years. Around $95 \%$ of the forested area in the Central India is of deciduous type, out of which around $36 \%$ of the forested area exhibited the very high deciduousness. Most of the study area consisting of the deciduous vegetation showed a positive relationship of the deciduousness with rainfall. However, the regions having evergreen, semi-evergreen and good ground water availability showed spatial variability in this relationship. The VHD class of deciduousness observed was low $(34.38 \%)$ in the dry year (2002), moderate $(42.38 \%)$ in the normal year (2011) and high (51.06\%) in the wet year (2013).

Under the low $(<1000 \mathrm{~mm})$ rainfall region, the deciduousness was lower (VHD area: $4.75 \%$ and HD area: $9.56 \%)$ than the high $(>1500 \mathrm{~mm}$ ) rainfall region (VHD area: $16.14 \%$ and HD area: $22.89 \%)$. The Narmada valley region experienced 7 dry periods during 2001-2008. Forests in the Narmada Valley and Eastern highlands 
regions revealed a significant rainfall dependency. The Chhota-Nagpur plateau and Northern dry deciduous regions revealed a random deciduous pattern, and rainfall dependency was not found significant.

A positive relationship between forest density and the deciduousness was observed only in the low density classes. Further, the VCF values were not the actual representation of the forest density classes. In fact, the VCF underestimated both the low and high forest density classes considerably. In terms of topographic elevation, the HD and VHD classes (54\% of the forested area) were observed mainly in the elevation zone of 300-600 m amsl.

Thus, it can be stated that the present study improved the spatial-temporal understanding of the deciduousness and its sensitivity to climatic extremes. This will help the ecologists to carry out further detailed ground survey in the sensitive zones. The findings of this study contribute towards the objectives of Long-Term Ecological Observatories (LETO) Programme initiatives launched in 2015 by the Indian Government to study and monitor health of the Central Indian forests. The information about the deciduousness behaviour at landscape will help forest managers to demarcate fire-prone zones. Forest fire models around the world can include the deciduousness as one of the parameters for predicting spatio-temporal spread of forest fire. Since, the deciduousness is the indicator of leave shedding phenomena, our study will help to model litter fall across the tropical deciduous forest. This in turn would help in understanding the vegetation dynamics and nutrients recycling of this ecosystem.

\section{Material and methods}

Study area. The study region i.e. the Central Indian forested landscape (Fig. 1) covers 5 Indian statesMaharashtra, Madhya Pradesh, Chhattisgarh, Odisha and Jharkhand. As per Forest Survey of India's (FSI) report $^{75}$, the Indian subcontinent contains around $21.54 \%\left(708,273 \mathrm{~km}^{2}\right)$ of forest cover (excluding trees outside the forested areas), and the Central Indian forest cover is about $7.86 \%\left(258,541 \mathrm{~km}^{2}\right)$. The total geographical area of these five states is $986,580 \mathrm{~km}^{2}$ and $26.20 \%$ of area consists of forest cover ${ }^{75}$. This tropical forested landscape exists amidst extensive human pressure. This landscape provides shelter for diverse life forms through 108 wildlife sanctuaries, 22 national parks 17 tiger reserve and 8 elephant reserves. Also, this landscape houses a series of protected forests connecting corridors for tigers and elephants which are meant to maintain the gene flow, species, and wildlife movement ${ }^{32}$.

The Central India receives its majority of rainfall ( 80\%) during southwest monsoon (June-September), and temperature varies from a minimum of $15^{\circ} \mathrm{C}$ in winter to a maximum of $45^{\circ} \mathrm{C}$ in summer. This landscape is under huge pressure from anthropogenic activities such as use of forest for fuel, fodder, timber, medicine, and other ecological services. The Central Indian forest landscape provides vast opportunities for researchers to take up diverse studies. As per FSI (2017), India's carbon stock was estimated to be 7083 million tons (Mt), and stock among major forest types like dry deciduous, moist deciduous, evergreen and semi-evergreen forest was $2670.34,1323.02,328.07$ and $1124.43 \mathrm{Mt}$, respectively ${ }^{75}$. The distribution of carbon stock in different states such as Maharashtra, Madhya Pradesh, Chhattisgarh, Odisha and Jharkhand of the study area was 493.02, 695.66, $560.98,452.90$, and $222.88 \mathrm{Mt}$, respectively.

MODIS data. Moderate Resolution Imaging Spectroradiometer (MODIS)-MOD13Q1 (Collection 6) Terra composite NDVI data (at 16 days interval and $250 \mathrm{~m}$ spatial resolution) were downloaded over 18 years (2001-2018) from LPDAAC (Land Processing Distributed Active Archive Center (https://lpdaac.usgs.gov). The MODIS standard VI products are atmospherically corrected for bi-directional surface reflectance and are masked for water, clouds, heavy aerosols, and cloud shadows ${ }^{76,77}$.

Climate hazards group infrared precipitation with station (CHIRPS) data. The CHIRPS data is the longest archive of precipitation datasets available at a global level which spans for more than $30+$ years on a monthly basis ${ }^{78}$. The data spans from $50^{\circ} \mathrm{S}-50^{\circ} \mathrm{N}$ latitudes and are available for all longitudes from 1981 onwards. For this study CHIRPS monthly datasets were downloaded for a period of 18 years (ftp://ftp.chg.ucsb. $\mathrm{edu} / \mathrm{pub} / \mathrm{org} / \mathrm{chg} /$ products/CHIRP/monthly/). The CHIRPS data version 2.0 at a spatial resolution of $0.05^{\circ}$ $(\sim 5 \mathrm{~km})$ was used in this study. The CHIRPS is the product of a collaborative project taken by the scientists working in US Geological Survey (USGS) and Earth Resources Observation and Science (EROS) for early warning system, and were created using precipitation estimates from satellite imagery merged with in-situ gauging stations data as a gridded rainfall time series ${ }^{79}$.

Other datasets. MODIS Vegetation Continuous Field (VCF) (MOD44B v006) and ASTER Global Digital Elevation Model (ASTGTM v003) products were also used in this study (see https://pdaac.usgs.gov for more details). The annual VCF product provides a percent tree cover information i.e., the total canopy of trees having $5 \mathrm{~m}$ or greater height, at a spatial resolution of $250 \mathrm{~m}$ across the globe (see https://pdaac.usgs.gov/products/ mod44bv006/ for more details). The VCF data helped to analyse the distribution of the deciduousness under different canopy cover categories. The DEM from ASTER is available at one arc second spatial resolution over $83^{\circ}$ North to $83^{\circ}$ South. This data helped to quantify the presence of forest and the deciduousness at different elevation zones. The most comprehensive vegetation type map prepared for the Indian subcontinents so far was by Roy et al. ${ }^{67}$ at $1: 50,000$ scale using the LISS III sensor $(23.5 \mathrm{~m})$ (https://bis.iirs.gov.in). From this map, we extracted all the classes of dry deciduous, moist deciduous, semi-evergreen, and evergreen forest types and converted all these classes into one single forest class. Then, this forest map was up-scaled to $250 \mathrm{~m}$ using threshold based aggregation procedure. For this purpose, the percentage of forest pixels (of size $23.5 \mathrm{~m}$ ) occurring within each of the $250 \mathrm{~m}$ MODIS grids was estimated, and the grids having $\geq 75 \%$ forest cover only were marked as forested grid. The final forest map derived at $250 \mathrm{~m}$ grid was used as forest mask for further analysis.

Terrestrial Ecoregions of the World (TEOW) is a biogeographic regionalization of the Earth's terrestrial biodiversity defined as relatively large units of land or water containing a distinct assemblage of natural communities 
sharing a large majority of species, dynamics, and environmental conditions ${ }^{45}$. The terrestrial ecoregion map of the world was downloaded from Data Basin website (https://databasin.org/datasets/). Out of the total 51 terrestrial ecoregions of India, 15 ecoregions falling within the study area were extracted and utilised in this study (Fig. S5).

Time-series data processing. The study area is covered by 6 MODIS tiles (i.e. h24v06, h24v07, h25v06, h25v07, h26v06, h26v07), and a total of 2484 images were acquired for 18 years (2001-2018). The overall methodology followed in this research is depicted in Fig. S8. The pixels having reliability flags 0 and 1 were only used for further analysis, while the rest of the unreliable pixels were discarded. The composites of all the tiles for each year were mosaicked, and only the forested pixels were processed.

At first, we filled the gaps, created due to the elimination of unreliable pixels, using appropriate noise-free temporal neighborhood values to keep the phenological trend unchanged. Then, we eliminated the erroneous values at each pixel using the statistical outlier removal technique ${ }^{55,56,79}$. The noise eliminated data sets were then smoothed using Discrete Fourier Transform (DFT) with initial six harmonics ${ }^{38,80}$.

Estimation of vegetation growth. Quantifying deciduousness. According to White and Nemani ${ }^{81}$ and Cuba et al. ${ }^{14}$, a pixel is dominantly deciduous if the amplitude (i.e. difference between minimum and maximum) of yearly VI profile in a pixel is greater than $50 \%$ of annual maximum (Fig. 2). We observed that this approach is falsely detecting the smaller height vegetation types (i.e., pheno-classes 3 and 4 in Fig. 2c) as highly deciduous. The following two equations (Eqs. 1, 2) were used to estimate the annual deciduousness (AD) which reveals the remote sensing derived proxy leaf fall percentage in a pixel. The Eq. (1) was given by Cuba et al. ${ }^{14}$ and the improved new metric is given in the Eq. (2).

$$
\begin{gathered}
\text { Annual Deciduousness }(\mathrm{Old})_{i, x, y}=\frac{\operatorname{Max}_{i, x, y}-\operatorname{Min}_{i, x, y}}{\operatorname{Max}_{i}, x, y} \times 100 \\
\text { Improved Annual Deciduousness }(A D)_{i, x, y}=\frac{\operatorname{Max}_{i, x, y}-\operatorname{Min}_{i, x, y}}{\operatorname{Max}_{i}, x, y} \times \frac{\operatorname{Mean}_{i, x, y}}{S_{c}}
\end{gathered}
$$

where, $i$ is the year, and (x,y) are the column and row positions. $\operatorname{Min}_{i, x, y,}, \operatorname{Max}_{i, x, y}$ and $\operatorname{Mean}_{i, x, y}$ are the minimum, maximum and mean NDVI value of a pixel at $(x, y)$ in ith year, respectively. $S_{c}$ is the scaling constant $\left(S_{c}=0.005\right)$. Expected values of AD i.e. theoretical minimum and maximum will be in the range of $0-100$.

The parameters involved in the deciduousness estimation are depicted graphically using an illustrative theoretical annual profile (Fig. 2a). A comparison of both the metrics was made using actual RS derived NDVI values from moist and dry deciduous samples (Fig. 2b) and 4 theoretical pheno-classes (Fig. 2c). The performance of the new and old metric was checked in different vegetation classes having high to low deciduousness categories using well distributed samples across the study area. If we consider deciduousness as a proxy litter fall, RS based deciduousness estimates must be relatively similar to the ground-based litter fall observation. In this regard, litter fall from different vegetation types in the study region was collected through literature review and was used to check the results from both the metrices. The degree of magnitude of growth in terms of deciduousness of tropical forest was examined during 2001-2018. In this study, unlike Cuba et al. ${ }^{14}$, we mapped and examined the variability of deciduousness in different climatic extremes and strata without applying any threshold value.

In order to compare the deciduousness estimated for different years within the study area, and to understand the climatic impact, we estimated relative annual deciduousness (RAD). But for this, we needed a reference benchmark deciduousness value. Thus, we considered the benchmark $\mathrm{AD}$ as the highest $\mathrm{AD}$ value at a pixel out of 18 years (referred as MaxAD $\mathrm{D}_{L T}$; LT is Long-Term). For the study area we needed a single representative benchmark deciduousness and hence we considered mean of $M a x D_{L T}$ of the entire study area. Finally, RAD was calculated by using the Eq. (3) where the constant 100 is used to convert deciduousness into a percentage.

$$
\text { Relative Annual Deciduouness }(R A D)_{i, x, y}=\frac{A D_{i, x, y}}{\operatorname{Mean}\left(\operatorname{Max} A D_{L T}\right)} \times 100
$$

The denominator is considered as the benchmark deciduousness for the study area. RAD is useful in understanding the $\mathrm{AD}$ variability in dry, wet and normal years.

Rainfall anomaly. There is no dearth of sunlight availability in the Central India, so the variation in the deciduousness would mainly depend upon the water availability. Therefore, to understand the variation in water availability in different years, spatial-temporal variability in the rainfall anomaly was estimated based on annual accumulated rainfall (AAR) for the years 2001-2018.

$$
\text { Percentage Rainfall Anomaly }(\mathrm{PRA})_{i}=\frac{A A R_{i}-A A R_{L T}}{A A R_{L T}} \times 100
$$

where, $\mathrm{AAR}_{i}$ represents Annual Accumulated Rainfall in ith year and $\mathrm{AAR}_{L T}$ represents the long-term mean AAR over 18 years. PRA was estimated at every pixel and used to check whether a year is a dry, wet or normal year. Also the correlation between AD and rainfall during 2001-2018 was estimated at every pixel. 
Stratified spatial analysis of deciduousness. The deciduousness of the landscape was analyzed for its variability with rainfall at different stratification levels: (a) Vegetation types, (b) Altitudinal zones (c) Vegetation Continuous Fraction and (d) Ecoregions wise.

Analysis of variance. In order to test the intra and inter year variability in the deciduousness values derived from (a) the old and new metric, (b) in dry and moist vegetation type and (c) in dry, wet and normal years, we utilized ANOVA statistics. Around 800 random samples were taken from the deciduous vegetated class (dry and moist forest types) and divided into 2 sample groups: first group was taken over pixels in the open to moderately dense forest having VCF density range of $<30 \%$ and the second group was taken over pixels in the dense forest having $\mathrm{VCF}>40 \%$.

\section{Data availability}

All the spatial datasets used in this are available in the web for downloading free of charge. All the resultant data used in this study are available from the authors upon request.

Received: 18 June 2020; Accepted: 30 September 2020

Published online: 19 October 2020

\section{References}

1. Cramer, W. et al. Tropical forests and the global carbon cycle: Impacts of atmospheric carbon dioxide climate change and rate of deforestation. Philos. Trans. R. Soc. B Biol. Sci. 359(1443), 331-343 (2004).

2. Beer, C. et al. Terrestrial gross carbon dioxide uptake: global distribution and covariation with climate. Science 329(5993), 834-838 (2010).

3. Salunkhe, O., Khare, P. K., Kumari, R. \& Khan, M. L. A systematic review on the aboveground biomass and carbon stocks of Indian forest ecosystems. Ecol. Process. 7(17), 1 (2018).

4. Anderson-Teixeira, K. J. et al. Climate-regulation services of natural and agricultural ecoregions of the Americas. Nat. Clim. Change 2(3), 177-181 (2012).

5. Richardson, A. D. et al. Climate change phenology and phenological control of vegetation feedbacks to the climate system. Agric. For. Meteorol. 169, 156-173 (2013).

6. Nepstad, D. C. et al. (1994) The role of deep roots in the hydrological and carbon cycles of Amazonian forests and pastures. Nature 372, 666-669 (1994).

7. Wang, M., Chen, Y., Wu, X. \& Bai, Y. Forest-type-dependent water use efficiency trends across the northern hemisphere. Geophys. Res. Lett. 1, 1. https://doi.org/10.1029/2018gl079093 (2018).

8. Spracklen, D. V. \& Righelato, R. Tropical montane forests are a larger than expected global carbon store. Biogeosciences 11, 2741-2754 (2014).

9. Westra, S. et al. Future changes to the intensity and frequency of short-duration extreme rainfall. Rev. Geophys. 1, 1. https://doi. org/10.1002/2014RG000464 (2014).

10. Naumann, G. et al. Global changes in drought conditions under different levels of warming. Geophys. Res. Lett. 45(7), 3285-3296 (2018).

11. Song, L. et al. Divergent vegetation responses to extreme spring and summer droughts in Southwestern China. Agric. For. Meteorol. 279, 107703 (2019).

12. Kushwaha, C. P., Tripathi, S. K., Singh, G. S. \& Singh, K. P. Diversity of deciduousness and phenological traits of key Indian dry tropical forest trees. Ann. For. Sci. 67, 310 (2010).

13. Xie, Z., Wang, L., Jia, B. \& Yuan, X. Measuring and modeling the impact of a severe drought on terrestrial ecosystem $\mathrm{CO}_{2}$ and water fluxes in a subtropical forest. J. Geophys. Res. Biogeosci. 121(10), 2576-2587 (2016).

14. Cuba, N. et al. Modelling dry season deciduousness in Mexican Yucatán forest using MODIS EVI data (2000-2011). GISci. Remote Sens. 50(1), 26-49 (2013).

15. Jeganathan, C., Dash, J. \& Atkinson, P. M. Remote Sensed trends in the phenology of northern high latitude terrestrial vegetation, controlling for land cover change and vegetation type. Remote Sens. Environ. 143, 154-170 (2014).

16. Zheng, Z. et al. Continuous but diverse advancement of spring-summer phenology in response to climate warming across the Qinghai-Tibetan Plateau. Agric. For. Meteorol. 223, 194-202 (2016).

17. Scranton, K. \& Amarasekare, P. Predicting phenological shifts in a changing climate. Proc. Natl. Acad. Sci. 114(50), 13212-13217 (2017).

18. Myneni, R. B., Keeling, C. D., Tucker, C. J., Asrar, G. \& Nemani, R. R. Increased plant growth in the northern high latitudes from 1981-1991. Nature 386, 698-702 (1997).

19. Nemani, R. R. et al. Climate driven increases in global terrestrial net primary production from 1982 to 1999 . Science 300, 1560-1563 (2003).

20. Julien, Y. \& Sobrino, J. A. Global land surface phenology trends from GIMMS database. Int. J. Remote Sens. 30, 3495-3513 (2009).

21. Jeong, S. J., Ho, C. H., Gim, H. J. \& Brown, M. E. Phenology shifts at start vs. end of growing season in temperate vegetation over the Northern Hemisphere for the period 1982-2008. Glob. Change Biol. 17, 2385-2399 (2011).

22. Rankine, C., Sanchez-Azofeifa, G.A., Guzman, J.A., Espirito-Santo, M.M., \& Sharp, I. (2017). Comparing MODIS and near-surface vegetation indexes for monitoring tropical dry forest phenology along a successional gradient using optical phenology towers. Environ. Res. Lett.12, 105007 (2017).

23. Gandolfi, S. et al. "Gaps of deciduousness": cyclical gaps in tropical forests. Sci. Agricola 66(2), 280-284 (2009).

24. Goswami, B. N. et al. Increasing trend of extreme rain events over india in a warming environment. Science 314(5804), 1442-1445 (2006).

25. Roxy, M.K. et al. A threefold rise in widespread extreme rain events over central India. Nature Commun.8 (708) (2017).

26. Mukherjee, S., Aadhar, S., Stone, D. \& Mishra, V. Increase in extreme precipitation events under anthropogenic warming in India. Weather Clim. Extremes 20, 45-53 (2018).

27. Kumar, P. V., Naidu, C. V. \& Prasanna, K. Inconsistency in the frequency of rainfall events in the Indian summer monsoon season. Int. J. Climatol. https://doi.org/10.1002/joc.6113 (2019).

28. Kumar, N. M. Spatio-temporal analysis of meteorological drought variability in the Indian region using standardized precipitation index. Meteorol. Appl. 19(2), 256-264 (2011).

29. Singh, B. \& Jeganathan, C. Spatio-temporal forest change assessment using time series satellite data in Palamu District of Jharkhand India. J. Indian Soc. Remote Sens. 44(4), 573-581 (2016).

30. DAC, FW. Drought Management Plan Government of India Ministry of Agriculture and Famers Welfare Department of Agriculture Cooperation and Farmers New Delhi (2017). 
31. Champion, H.G. \&Seth, S.K. A Revised Survey of the Forest Types of India Government of India. Publication New Delhi (1968).

32. Sharma, S. et al. Forest corridors maintain historical gene flow in a tiger metapopulation in the highlands of central India. Proc. R. Soc. B Biol. Sci. 280, 20131506 (2013).

33. Hunter, J. R. Tendu (Diospyros melanoxylon) leaves bidi cigarettes and resource management economic. Botany 35(4), 450-459 (1981).

34. Saxena, N.C. Livelihood Diversification and Non-Timber Forest Products in Orissa: Wider Lessons on the Scope for Policy Change? ODI Working Paper No 223 Overseas Development Institute London UK (2003).

35. Mahadule, D.K. \& Vimmy. Addressing Rural Poverty Through NTFP: A Case Study of Madhya Pradesh Research Study Report: Delhi School of Economics University of Delhi (2011).

36. Singh, K. P. \& Kushwaha, C. P. Deciduousness in tropical trees and its potential as indicator of climate change: a review. Ecol. Ind. 69, 699-706 (2016).

37. Mishra, R. K. et al. Phenology of species of moist deciduous forest sites of Similipal biosphere reserve. Lyonia 11(1), 5-17 (2006).

38. Jeganathan, C., Dash, J. \& Atkinson, P. M. Characterising the spatial pattern of phenology for the tropical vegetation of India using multi-temporal MERIS chlorophyll data. Landscape Ecol. 25(7), 1125-1141 (2010).

39. Kumar, B. M. \& Deepu, J. K. Litter production and decomposition dynamics in moist deciduous forests of the Western Ghats in Peninsular India. For. Ecol. Manage. 50(34), 181-201 (1992).

40. Gupta, R. \& Raut, S.K. Litter dynamics and nutrient turn over in a mixed deciduous forest In Tropical Ecosystems: Ecology and Management (eds). Singh K P and Singh J S Wiley Eastern New Delhi India (1992).

41. Thakur, T. K. \& Thakur, A. Litterfall patterns of a dry tropical forest ecosystem of central India. Ecol. Environ. Conserv. 20(3), 1-4 (2014).

42. Bhattarai, K. \& Mandal, T. Comparative study on litter production and nutrient return to soil in Tarai and Hill Sal (Shorea robusta Gaertn) forests of eastern Nepal. Banko Janakari 28(1), 11-19 (2018).

43. Singh, K.P. Litter production and nutrient turnover in deciduous forests of Varanasi In: Proceedings of Symposium on Recent Advances in Tropical Eco-logy (eds) Misra R and Gopal B. International Society of Tropical Ecology Varanasi 655-665 (1968).

44. Sundarapandian, S. M. \& Swamy, P. S. Litter production and leaf-litter decomposition of selected tree species in tropical forests at Kodayar in the Western Ghats India. For. Ecol. Manage. 123, 231-244 (1999).

45. Olson, D. M. et al. Terrestrial ecoregions of the world: a new map of life on Earth. Bioscience 51(11), 933-938 (2001).

46. Feng, X., Porporato, A. \& Rodriguez-Iturbe, I. Changes in rainfall seasonality in the tropics. Nat. Clim. Change 3, 811-815 (2013).

47. Manzoni, S., Vico, G., Thompson, S., Beyer, F. \& Weih, M. Contrasting leaf phenological strategies optimize carbon gain under droughts of different duration. Adv. Water Resour. 84, 37-51 (2015).

48. Gradstein, R.S., Homeier, J. \& Gansert, D. Tropical mountain forest: patterns and processes in a biodiversity hotspot Akron: University of Akron Press $224 \mathrm{p}$ (2004).

49. Clark, D. B., Hurtado, H. \& Saatchi, S. S. Tropical rain forest structure tree growth and dynamics along $2700 \mathrm{~m}$ elevational transect in costa Rica. PLoS ONE 10(4), e0122905 (2015).

50. Sonnentag, O. et al. Spatially explicit simulation of peatland hydrology and carbon dioxide exchange: influence of mesoscale topography. J. Geophys. Res. 113, G02005 (2008).

51. Runkle, B. R. K. et al. Bulk partitioning the growing season net ecosystem exchange of $\mathrm{CO}_{2}$ in Siberian tundra reveals the seasonality of its carbon sequestration strength. Biogeosciences 10, 1337-1349 (2013).

52. Zhou, S. et al. Partitioning evapotranspiration based on the concept of underlying water use efficiency. Water Resour. Res. 52, $1160-1175$ (2016).

53. Jeganathan, C., Dash, J. \& Atkinson, P. M. Mapping the phenology of natural vegetation in India using a remote sensing derived chlorophyll index. Int. J. Remote Sens. 31(22), 5777-5796 (2010).

54. Pande, P. K., Meshram, P. B. \& Banerjee, S. K. Litter production and nutrient return in tropical dry deciduous teak forests of Satpura plateau in central India. Trop. Ecol. 43(2), 337-344 (2002).

55. Yadav, M. \& Basera, K. Status of forest products production and trade. Working Paper Centre for Sustainable Forest Management and Forest Certification Indian Institute of Forest Management Bhopal (2013).

56. Newton, P. N. The structure and phenology of a moist deciduous forest in the central Indian Highlands. Vegetatio 75(1-2), 3-16 (1988).

57. Kushwaha, C. P. \& Singh, K. P. Diversity of leaf phenology in tropical deciduous forest in India. J. Trop. Ecol. 21(1), 47-56 (2005).

58. Verma, R., Kumar, V., Agarwal, R. K. \& Gupta, S. R. Diversity of leaf phenology of tree species in a mixed dry deciduous forest of Orchha Madhya Pradesh. Ann. Forestry 15(2), 207-219 (2007).

59. Jeganathan, C. \& Nishant, N. Scrutinising MODIS and GIMMS vegetation indices for extracting growth rhythm of natural vegetation in India. J. Indian Soc. Remote Sens. 42(2), 397-408 (2014).

60. Parihar, J. S. et al. Observation of forest phenology using field-based digital photography and satellite data. Curr. Sci. 105(12), $1740-1746$ (2013).

61. Elliott, S., Baker, P. J. \& Borchert, R. Leaf flushing during the dry season: the paradox of Asian monsoon forests. Glob. Ecol. Biogeogr. 15, 248-257 (2006).

62. Williams, L. J., Bunyavejchewin, S. \& Baker, P. J. Deciduousness in a seasonal tropical forest in western Thailand: interannual and intraspecific variation in timing duration and environmental cues. Oecologica 155(3), 571-582 (2008).

63. Felton, A. J. \& Smith, M. D. Integrating plant ecological responses to climate extremes from individual to ecosystem levels. Philos. Trans. R. Soc. B Biol. Sci. 372(1723), 20160142 (2017).

64. Kunhamu, T. K., Kumar, B. M. \& Viswanath, S. Does thinning affect litterfall, litter decomposition and associated nutrient release in Acacia mangium stands of Kerala in peninsular India?. Can. J. For. Res. 39(4), 792-801 (2009).

65. Jeganathan, C., Dadhwal, V. K., Gupta, K. \& Raju, P. L. N. Comparison of MODIS vegetation continuous field based forest density maps with IRS-LISS III derived maps. J. Indian Soc. Remote Sens. 37(4), 539-549 (2009).

66. Singh, K. P. \& Kushwaha, C. P. Paradox of leaf phenology: Shorea robusta is a semi-evergreen species in tropical dry deciduous forests in India. Curr. Sci. 88(11), 1820-1824 (2005).

67. Roy, P. S. et al. New vegetation type map of India prepared using satellite remote sensing: comparison with global vegetation maps and utilities. Int. J. Appl. Earth Obs. Geoinf. 39, 142-159 (2015).

68. Condit, R. et al. Quantifying the deciduousness of tropical forest canopies under varying climates. J. Veg. Sci. 11, 649-658 (2000).

69. Duan, S., He, H. \& Septic, M. Effects of growing-season drought on phenology and productivity in the west region of central hardwood forests USA. Forests 9 (7), 377 (2018).

70. Saatchi, S. et al. Persistent effects of a severe drought on Amazonian forest canopy. Proc. Natl. Acad. Sci. 110(2), 565-570 (2013).

71. Raju, B. M. K. et al. Revisiting climatic classification in India: a district-level analysis. Curr. Sci. 105(4), 492-495 (2013).

72. Wu, D. et al. Time-lag effects of global vegetation responses to climate Change. Global Change Biol. 1, 1. https://doi.org/10.1111/ gcb12945 (2015).

73. Zhao, W. et al. Climatic factors driving vegetation declines in the 2005 and 2010 Amazon droughts. PLoS ONE 12(4), e0175379 (2017).

74. Sarmah, S., Jia, G. \& Zhang, A. Satellite view of seasonal greenness trends and controls in South Asia. Environ. Res. Lett. 13, 034026 (2018).

75. ISFR. State of Forest Report Forest Survey of India Ministry of Environment and Forests Government of India Dehradun (2017). 
76. Huete, A. Overview of the radiometric and biophysical performance of the MODIS vegetation indices. Remote Sens. Environ. 83(1-2), 195-213 (2002).

77. Didan, K., Barreto, A., Solano, R. \& Huete, A. MODIS vegetation index user's guide (MOD13 Series) version 3.00 (Collection 6 ) (2015).

78. Funk, C. et al. The climate hazards infrared precipitation with stations: a new environmental record for monitoring extremes. Sci. Data 2, 150066 (2015)

79. Dinku, T. et al. Validation of the CHIRPS satellite rainfall estimates over eastern Africa. Q. J. R. Meteorol. Soc. 1, 1. https://doi. org/10.1002/qj3244 (2018)

80. Atkinson, P. M., Jeganathan, C., Dash, J. \& Atzberger, C. Inter-comparison of four models for smoothing satellite sensor time-series data to estimate vegetation phenology. Remote Sens. Environ. 123, 400-417 (2012).

81. White, M. A. \& Nemani, R. R. Real-time monitoring and short-term forecasting of land surface phenology. Remote Sens. Environ. 104(1), 43-49 (2006).

\section{Acknowledgements}

Thanks to NASA (Land Processing Distributed Active Archive Centre) for the MODIS, USGS for DEM data, and Climate Hazard Group, University of California Santa Barbara (UCSB) for the CHIRPS data. We acknowledge and thank Birla Institute of Technology (BIT, Mesra, Ranchi) for the financial support to B. Singh (Ref. No. OO/ Estb/Ph.D/2017-18/2772) and needed administrative support for carrying out this study. We also acknowledge the TEQIP-III project for supporting towards processing fee of this publication. Thanks to Google Earth for helping the global researchers with their platform. Thanks to Conservation Biology Institute and Dr. Oslon for sharing the Terrestrial Ecoregions of the World. Thanks to Dr. P.S. Roy and Forest Survey of India (FSI) for providing the forest related information. Thanks to all the anonymous reviewers for their valuable comments and suggestions which have greatly helped in improving the manuscript.

\section{Author contributions}

B.S. and C.J. designed the study. B.S., C.J. and V.S.R. participated in the data analysis. B.S. created figures with the guidance of C.J. and V.S.R. All the authors wrote and reviewed the manuscript, discussed results and approved the final version.

\section{Competing interests}

The authors declare no competing interests.

\section{Additional information}

Supplementary information is available for this paper at https://doi.org/10.1038/s41598-020-74563-2.

Correspondence and requests for materials should be addressed to C.J.

Reprints and permissions information is available at www.nature.com/reprints.

Publisher's note Springer Nature remains neutral with regard to jurisdictional claims in published maps and institutional affiliations.

(c) (i) Open Access This article is licensed under a Creative Commons Attribution 4.0 International License, which permits use, sharing, adaptation, distribution and reproduction in any medium or format, as long as you give appropriate credit to the original author(s) and the source, provide a link to the Creative Commons licence, and indicate if changes were made. The images or other third party material in this article are included in the article's Creative Commons licence, unless indicated otherwise in a credit line to the material. If material is not included in the article's Creative Commons licence and your intended use is not permitted by statutory regulation or exceeds the permitted use, you will need to obtain permission directly from the copyright holder. To view a copy of this licence, visit http://creativecommons.org/licenses/by/4.0/.

(c) The Author(s) 2020 